\title{
Novel surface coating strategies for better battery materials
}

1 Lei Wen PhD

Associate Professor, Shenyang National Laboratory for Materials Science, Institute of Metal Research, Chinese Academy of Sciences, Shenyang, China

2 Xiaowei Wang MSc

PHD student, Institute for Superconducting and Electronic Materials, Australian Institute of Innovative Materials, University of Wollongong, Wollongong, Australia

3 Guo Qiang Liu PhD

Professor, School of Metallurgy, Northeastern University, Shenyang, China (corresponding author: liugq@smm.neu.edu.cn)
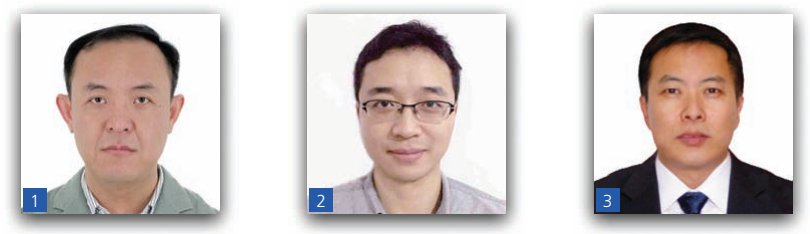
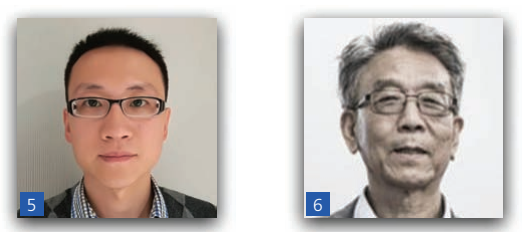

With the advancement of electrode materials for lithium-ion batteries (LIBs), it has been recognized that their surface/interface structures are essential to their electrochemical performance. Therefore, the engineering of their surface by various coating technologies is the most straightforward and effective strategy to obtain the desirable battery characteristics. Coating the electrode materials' surface to form a specifically designed structure/composition can effectively improve the stability of the electrode/electrolyte interface, suppress structural transformation, improve the conductivity of the active materials and consequently lead to enhanced cycle stability and rate capability of LIBs. However, due to the restrictions of conventional coating methods, it is still very hard to obtain a conformal and multifunctional coating layer. This paper focuses on recent advances and summarizes the challenges in the development of surface coating technologies for LIBs. Based on these factors, the new concepts of "ultrathin conformal coating', 'continuous phase coating' and 'multifunctional coating' are proposed and discussed, followed by the authors' rational perspectives on the future development and potential research hot spot in the surface/ interface engineering of LIB materials and systems.

\section{Introduction}

Lithium (Li)-ion batteries (LIBs) are the most widely used secondary power supply for portable electric/electronic devices due to their high energy density, negligible memory effect and low self-discharge. However, to meet the demands of various newly emerging energy storage applications, such as electric vehicles and intermittent energy harvest/storage systems (in particular renewable energy - for example, wind power, solar and hydraulic energy), the performance of LIBs needs to be pushed further to achieve even higher energy/power density, more stable and longer cyclability, faster charging/discharging rate and better safety. ${ }^{1}$ Thus, the research and development of the new LIB materials and battery systems have attracted extensive attention. Unfortunately, none of these new materials/systems have been successfully deployed in the present commercial LIB market. ${ }^{2}$ Lithium-sulfur (S) and lithium-air batteries are claimed as the most promising systems because of their much higher theoretical specific energy density; however, they are still far from being ready for mass commercialization unless the several critical shortcomings are solved with suitable ease and cost parameters. ${ }^{3}$

The typical well-developed lithium-transition-metal-oxide-based cathode materials (e.g. lithium cobalt oxide $\left(\mathrm{LiCoO}_{2}\right)$, lithium manganese oxide $\left(\mathrm{LiMn}_{2} \mathrm{O}_{4}\right)$ spinel, lithium nickel manganese cobalt oxide $\left(\mathrm{LiNi}_{1 / 3} \mathrm{Mn}_{1 / 3} \mathrm{Co}_{1 / 3} \mathrm{O}_{2}\right)$, lithium nickel cobalt aluminum $\left(\mathrm{LiNi}_{0 \cdot 8} \mathrm{Co}_{0 \cdot 15} \mathrm{O}_{2}\right)$ and lithium iron phosphate $\left.\left(\mathrm{LiFePO}_{4}\right)\right)$ and graphite anode materials are still the dominant electrode materials for commercial LIBs. For these, the engineering of their surface (i.e. the interface between the material and the electrolyte after packaged in a cell) by various coating technologies is the most straightforward and effective strategy to obtain the aforementioned desirable battery characteristics. Based on their roles in a battery, the functionalities of surface coatings can be categorized into three main types, which are described as follows (Figure 1). 


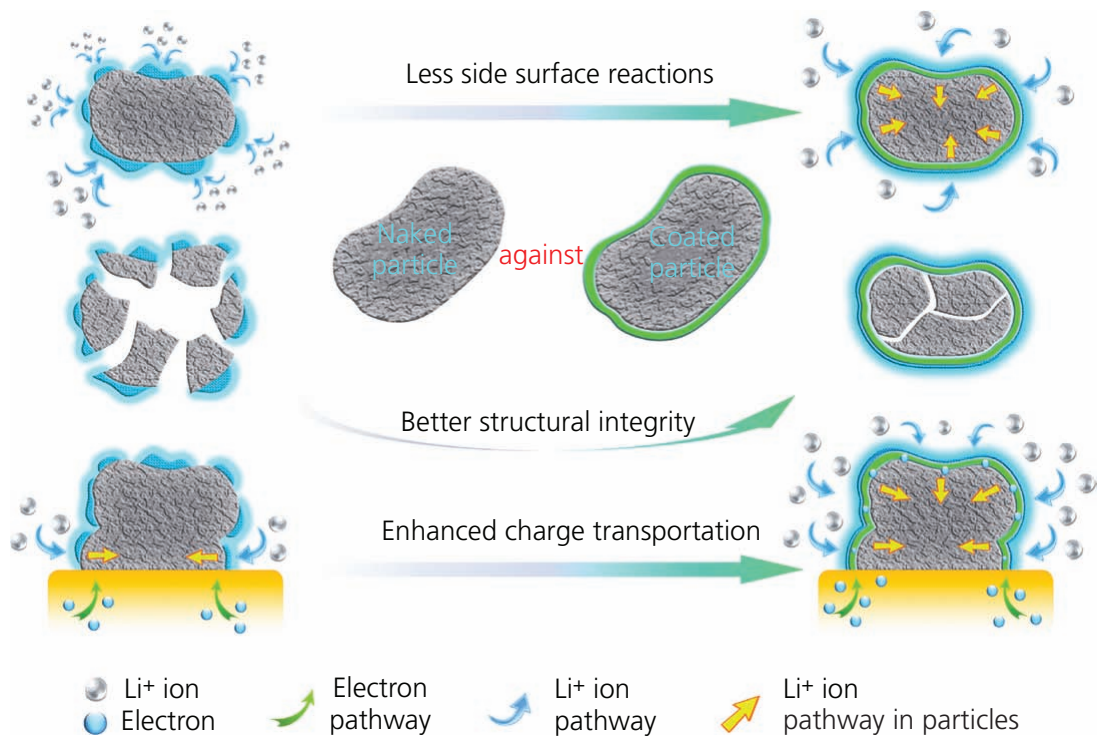

Figure 1. Functions of surface coating for LIB materials

The first functionality of the surface modification of electrode materials is to suppress the side reactions on their surface in the battery's operating environments. Due to the high working potentials, the cathode materials for LIBs usually suffer from transition-metal dissolution, phase transformation and electrolyte decomposition. Surface-coated cathodes have been demonstrated to be effective in blocking these surface processes and enhancing the electrochemical performance of the materials. For example, the electron-insulating but ion-conducting lithium carbonate $\left(\mathrm{Li}_{2} \mathrm{CO}_{3}\right)$ has been selected as the coating material for a commercial lithium cobalt oxide cathode ${ }^{4}$ Lithium carbonate is a well-known constituent for the conventional solid/electrolyte interface (SEI) layer, which can electrochemically protect the electrode. The magnetron-sputtered lithium carbonate layer can impede the formation of the primary SEI layer. With this protective coating, even when increasing the charging potential up to $4.7 \mathrm{~V}$ or elevating the operation temperature to $55^{\circ} \mathrm{C}$, lithium cobalt oxide electrodes still deliver remarkably improved cycling stability, compared with bare lithium cobalt oxide. In another case, it was found that aluminum oxide $\left(\mathrm{Al}_{2} \mathrm{O}_{3}\right)$ at the surface region of lithium cobalt oxide particles also leads to enhanced structural stability during cycling, and this is believed to originate from the suppression of the undesirable phase transition of lithium cobalt oxide from hexagonal to monoclinic phase. ${ }^{5}$

For anode materials, it is generally accepted that the side reactions (e.g. the decomposition of electrolytes) between electrode/ electrolyte interfaces play a major role in the capacity fading of LIBs during cycling. Due to this, an SEI layer forms on the graphite anode surface during the operation of LIBs. ${ }^{6}$ It has been known that this SEI layer has a significant contribution on the irreversible initial capacity loss, rapid self-discharge, unstable cycle life, low rate capability and poor safety of LIBs. ${ }^{7}$ Therefore, it is necessary to coat a dense pyrolytic carbon layer on the surface of the graphite anode to impede SEI formation, improve interface stability and increase the first-cycle coulumbic efficiency. ${ }^{8,9}$ Another typical anode is the zero-strained lithium titanate $\left(\mathrm{Li}_{4} \mathrm{Ti}_{5} \mathrm{O}_{12}\right)$ anode material, on whose surface the electrolyte will gradually decompose to release gases (e.g. carbon dioxide $\left(\mathrm{CO}_{2}\right)$, carbon monoxide $(\mathrm{CO})$ and hydrogen $\left.\left(\mathrm{H}_{2}\right)\right)$ due to its high interfacial activity. ${ }^{10,11}$ To improve its interfacial stability, a series of surface coatings has been applied, including pyrolytic carbon coating, ${ }^{12}$ aluminum fluoride $\left(\mathrm{AlF}_{3}\right)$ coating ${ }^{13}$ and oxide coating, ${ }^{14}$ which was used to protect the active surfaces and hinder gas formation.

Another function of the surface coating on the electrode materials is to improve their structural integrity during the prolonged cycling, particularly for high-capacity materials. More or less, volume variation of electrode materials occurs during the cycling. For example, graphite shows about $10 \%$ volume change, whereas a tin (Sn) alloy anode shows up to $200 \%$ and a silicon (Si) anode can reach as high as $400 \%$, resulting in a very fast capacity decay. ${ }^{15}$ Applying a layer of rigid carbon and/or elastomeric polymer on the surface of these high-capacity silicon and tinbased anode materials will prevent them from collapsing and thus significantly improve their cycling performance. ${ }^{16,17}$ For example, Wang et al. ${ }^{18}$ reported that the cycling performance of a silicon anode can be significantly improved by coating a self-healing polymer on its surface. This concept is also applicable to other battery systems with similar issues. In a lithium-sulfur cell system, the massive volume expansion of sulfur cathode (up to $80 \%$ ) and polysulfide dissolution during the cycle result in the rapid fading of capacity. The cycling performance of lithium-sulfur batteries can be significantly improved by coating carbon, nitride or a polymer on the sulfur surface. ${ }^{19-21}$ 
Moreover, surface coating of electrode materials can also improve their ion/electron conductivity, which is essential for their rate performance. It has also been noticed that most LIB electrode materials have very poor electrical conductivity (e.g. lithium iron phosphate and lithium titanate are almost insulators). ${ }^{22,23}$ In this regard, surface coating of the electrode active materials with a conductive layer is an economical and feasible solution that can effectively improve the electronic and/or ionic conductivity of pristine materials. For example, high-electron-conductivity carbon, conductive polymer and nitrides have been coated on the surface of lithium iron phosphate ${ }^{24}$ and lithium titanate ${ }^{25,26}$ materials, leading to a significantly improved high rate performance of these materials.

Briefly, coating treatments can significantly improve the performance of electrode materials for LIBs. Currently oftenused coating technologies include chemical methods (e.g. coprecipitation, surface nitration/carbonization, chemical vapor deposition and sol-gel method) and physical methods (e.g. atomic layer deposition (ALD) deposition and mechanical mixing). Surface coating techniques have been widely used in the LIB industry. Well-commercialized surface-coated LIB materials include carbon-coated graphite anode, carbon-coated lithium iron phosphate and lithium titanate materials and oxide-coated lithium cobalt oxide and lithium nickel cobalt aluminum materials.

Despite the various coating methods that have been developed or even applied to commercial LIB materials, there are still several critical issues that remain challenging. These mainly include three aspects. The first one is the control of coating uniformity: it is very difficult to get a uniform, dense and highly conformal coating layer by traditional wet-chemical or mechanical coating methods, and the uncoated sections will be exposed to the electrolyte, causing undesirable performance decay of LIBs. ${ }^{27}$ This is also associated with the difficulty of precisely controlling the coating thickness: the thickness of the coating layer by the conventional methods (up to tens of nanometers) is generally too thick, which will impede lithium-ion transportation and cause deteriorated battery performance, particularly at high rates. ${ }^{28}$ The second issue is the lattice mismatch between the electrode material and the surface coatings, which may result in the detachment of the coating layer from the bulk materials during repeated cycling. The third challenge is the hardness of obtaining a multipurpose coating that comes with two or more functionalities, as most of the current coating technologies provide only a monofunctional coating.

Aimed at these issues, future surface coating techniques are expected to endow LIB materials with higher stability, durability and rate capability. Figure 2 shows technological trends and possible applications of future surface coating techniques for LIB materials. Specifically, the following aspects - namely, ultrathin conformal coating, continuous phase coating and multifunctional coating - are particularly feasible for tackling these issues. They may attract the focus of research and become potential hot spots.

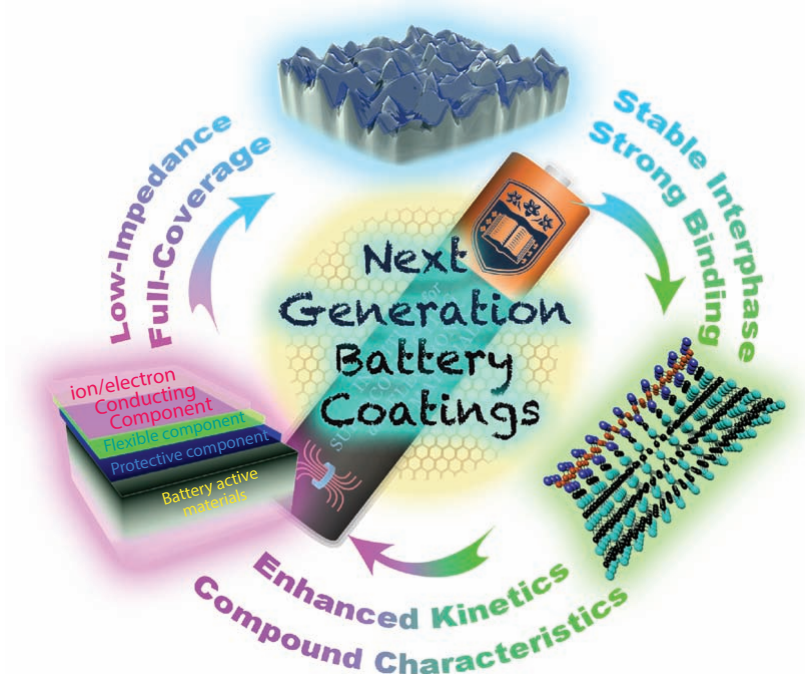

Figure 2. Future surface coating techniques and their relative impact on the materials' characterizations

\section{Ultrathin conformal coating}

Conventional coating technologies are normally incapable of precisely controlling the thickness and morphology of the coated layers. As a result, battery performance is frequently unstable, particularly between different batches of products. The newly developed ultrathin conformal coating technologies are particularly advantageous in this and other aspects. First, a uniform and ultrathin coating can create an ultrathin layer that fully isolates the electrode materials from the electrolyte but allows the lithium ions and electrons to penetrate easily without significantly increasing the impedance. Second, a conformal coating layer on granular materials will exactly resemble the morphology of the particle and possess a pinhole-free structure, so that electrode degradation can be largely decreased in the battery.

By far, a number of technologies have been developed for this task, such as ALD, magnetron sputtering and kinetic control coating. Recently, the ALD technology has attracted great interest as a novel tool for modifying electrode properties by way of ultrathin surface coating. ALD is a surface-controlled process, in which the deposition of films is dictated by alternative selfterminating and gas-solid surface reactions. ${ }^{29}$ By the ALD method, atomic scale ultrathin coatings (usually in several nanometers) with excellent uniformity, flexibility and conformity can be easily obtained. The thickness of the deposited layer can be controlled by adjusting the ALD cycles. In contrast, the coatings produced by conventional chemical methods are usually in the range of several hundreds of nanometers thick. Coatings obtained from ALD mainly include oxides (e.g. aluminum oxide, zirconium dioxide $\left(\mathrm{ZrO}_{2}\right)$, titanium dioxide $\left(\mathrm{TiO}_{2}\right)$ and zinc oxide $\left.(\mathrm{ZnO})\right)$ and nitrides (e.g. titanium nitride (TiN)). The most widely used ALD coating material is aluminum oxide, which uses trimethylaluminum and water as the precursors. ${ }^{30}$ For example, conformal and nanometric aluminum oxide coatings on nanosized lithium cobalt oxide 
cathode material, which is prepared by ALD, effectively increases the voltage window and rate performances compared to uncoated micro- and nanosized particles. ${ }^{31}$ ALD has also been used to deposit zirconium dioxide on lithium titanate anode material to improve its electrochemical performance, resulting in higher specific capacity, better cycling and rate performance. ${ }^{32}$ Lithiumion-conducting solids, such as lithium aluminate $\left(\mathrm{LiAlO}_{2}\right)$, have also been coated on the surface of lithium nickel cobalt aluminum or graphite materials by ALD. Due to its fast lithium-ion transport kinetics, this novel lithium-ion conductor provides a thin but stable barrier against the side reactions without compromising the lithium-ion transfer at the interface. ${ }^{33}$

However, one of the major drawbacks of the ALD method is its high cost and extremely low efficiency, which is unsuitable for mass production. As aforementioned, although various wetchemical methods have been widely used to coat LIB materials, it is still a huge challenge to form an ultrathin and uniform layer on the surface of materials, due to the fast kinetics of the common wetchemistry methods. Therefore, it is necessary to develop a highly controllable chemical coating process to obtain the desired ultrathin layer with a relatively high yield. For example, by carefully controlling the kinetics during the precipitation of aluminum phosphate $\left(\mathrm{AlPO}_{4}\right)$, a core-shell-structured $\mathrm{LiCoO}_{2} @ \mathrm{AlPO}_{4}$ can be obtained and the thickness of the aluminum phosphate coating can be tuned from 10 to $90 \mathrm{~nm}^{28}$ In another case, iron (III) phosphate $\left(\mathrm{FePO}_{4}\right)$ particles were coated with a very thin layer of polyaniline through an in situ polymerization method, and this composite was subsequently transformed into lithium iron phosphate with an ultrathin and semigraphitic carbon shell $(1-2 \mathrm{~nm})$ by pyrolysis in the presence of lithium salts. ${ }^{34}$

Compared with conventional coating techniques, these ultrathin coating processes can uniformly and conformally coat the surface of the electrodes with precise control of the composition and thickness. These ultrathin layers will modify only the surface of the electrode materials, and the change in materials' bulk properties will thus be minimized. ${ }^{35}$

\section{Continuous phase coating}

In order to improve the cycling performance of the electrode materials, various oxides (e.g. aluminum oxide, magnesium oxide $(\mathrm{MgO})$, zinc oxide, $\mathrm{MPO}_{4}(\mathrm{M}=$ cobalt $(\mathrm{Co})$, iron $(\mathrm{Fe})$, nickel (Ni)) and zirconium dioxide), fluorides (e.g. ammonium fluoride $\left(\mathrm{NH}_{4} \mathrm{~F}\right)$ and aluminum fluoride) and binary oxides (e.g. lithium aluminate, lithium pyrophosphate $\left(\mathrm{Li}_{4} \mathrm{P}_{2} \mathrm{O}_{7}\right)$, yttrium aluminum garnet $\left(\mathrm{Y}_{3} \mathrm{Al}_{5} \mathrm{O}_{12}\right)$ and magnesium aluminate $\left.\left(\mathrm{MgAl}_{2} \mathrm{O}_{4}\right)\right)$ have been utilized as the coating layers, which are mainly expected to prevent electrolyte decomposition under high potentials. However, a huge volume change mismatch upon lithiation/delithiation frequently exists at the interface between the coating and the pristine materials, which leads to a weak interface bonding between these two phases and the easy detachment of the coatings during the cycling. For example, a manganese (Mn)-rich coating was prepared on a nickel-rich cathode material (Li
$\left.\left(\mathrm{Ni}_{0 \cdot 8} \mathrm{Co}_{0 \cdot 1} \mathrm{Mn}_{0 \cdot 1}\right) \mathrm{O}_{2}\right)$, which was supposed to improve its specific capacity and safety characteristics. ${ }^{36}$ However, during the cycling, the nickel-rich bulk core shrank, whereas the outer layer expanded, causing inner cracks at the interface sections and deteriorated performance. Fundamentally, this volume change mismatch and poor bonding strength are caused by the diffusioninduced stresses among the nickel, cobalt and manganese atoms at the interface between the bulk and the outer layer during the hightemperature heat treatment.

In order to avoid this, the volume change mismatch between the coating layer and the bulk phase should be minimized. Compared with a heterogeneous phase coating, it is more desirable to form a continuous phase coating with a gradually evolved crystal structure that has a similar volume change during charging/ discharging processes. For example, a nanofunctional and fullgradient approach has been developed to prepare a nickel-rich lithium transition-metal (manganese and cobalt) oxide material, in which the manganese concentration gradually increases but the nickel and cobalt concentration decreases linearly from the center to the surface. ${ }^{37}$ These gradient materials have a continuously and gradually converted crystal structure, which significantly reduces the volume change mismatch between the coated phases and pristine materials. This strategy has also been applied to coat spinel lithium manganese oxide by a concentration-gradient layer with a continuously increasing nickel content to form finally a surface layer of $\mathrm{LiMn}_{1.5} \mathrm{Ni}_{0.5} \mathrm{O}_{4}$. Due to the same crystal structure of lithium manganese oxide and $\mathrm{LiMn}_{1 \cdot 5} \mathrm{Ni}_{0.5} \mathrm{O}_{4}$, this material is homogeneous without any apparent gaps/cracks between the inner core and the outer coating. The final coated materials thus show excellent capacity stability even at $55^{\circ} \mathrm{C}$, in which condition a traditional lithium manganese oxide material inevitably fails. ${ }^{38,39}$

Briefly, what makes continuous phase coating interesting for LIB development is that such coating strategy can significantly maintain the integrity of materials under electromechanical stress, particularly on the particle levels. Furthermore, it also helps improve the surface coverage of the coatings on materials due to their similar gradient composition. ${ }^{40}$

\section{Multifunctional coating}

An ideal coating should meet many requirements, which mainly include (a) high electronic conductivity, (b) high ionic conductivity, (c) the ability to protect materials from acid attack (e.g. hydrofluoric acid (HF) formed from the decomposed electrolyte) and $(d)$ good flexibility. Nevertheless, it is extremely difficult for a single coating layer to meet these requirements fully, due to the complicated physical and chemical processes inside LIBs. For example, a carbon coating has good electrical conductivity but lacks ionic conductivity. Although an oxide coating can significantly improve the stability of the electrode materials at high potential, its electronic conductivity is often very low. Despite that, a polymer coating can effectively buffer the volumetric variation of silicon or other alloy anode materials; these coatings usually show low ionic and/or electronic conductivity. 
To deal with these issues, the multiphase coating method could be a potential solution. In one case, lithium iron phosphate cathode materials were coated with a mixture of lithium phosphate $\left(\mathrm{Li}_{3} \mathrm{PO}_{4}\right)$ and carbon, which resulted in an improved rate capability compared with carbon-coated lithium iron phosphate. In this architecture, lithium phosphate and carbon possess excellent ion and electronic conductivity, respectively. Consequently, the resultant lithium phosphate/carbon hybrid coating showed much decreased interfacial impedance. ${ }^{41}$ In another study, a graphene/ aluminum oxide hybrid coating was introduced to prepare silicon composite anode materials. Crystalline silicon particles were firstly deposited onto graphene sheets by using liquid chlorosilane as silicon source. Then, an aluminum oxide layer was directly deposited on the silicon-graphene composite. In this configuration, graphene was used as a flexible buffer to neutralize the huge volume expansion of silicon particles. At the meantime, the side reactions between the electrode and electrolyte were suppressed by the aluminum oxide layer. Consequently, this design results in a remarkable enhancement in the initial efficiency and reversible capacity. ${ }^{42}$

\section{Conclusion and perspective}

Consumers are constantly demanding lighter, safer and spaceeffective LIBs. Such demands will continue to generate numerous research activities toward the development of electrode materials. Among different modification methods, surface coating plays an important role in the modification of LIB materials, which significantly improves the cycling and rate performance of LIBs and shows potential applications for the newly emerged lithium-sulfur or lithium-air/oxygen $\left(\mathrm{O}_{2}\right)$ systems. Application of surface coating in LIB materials has three aspects: $(a)$ the coating layer acting as a protecting phase to enhance the stability of the materials, $(b)$ buffer volume expansion during charging/discharging processes and (c) improvement of electronic/ionic conductivity. However, due to the restrictions of conventional coating methods, it is still very hard to obtain a conformal and multifunctional coating layer. Therefore, in order to achieve the desired functionalities, it is necessary to design and control precisely the structure and chemical compositions of the interface between the coating phases and the pristine materials. The future of the new coating technology will focus on ultrathin, uniform, continuous and multifunctional coating and other combinations to integrate their merits. Thus, diversified coating methods need to be developed, such as ALD and kinetics-controlled wet-chemical methods. Although there are still many problems to solve, the ubiquitous applications of surface coating technologies with low cost and convenience are very much anticipated in the near future. Ultimately, the performance of these coated materials will completely exceed that produced by the conventional coating process.

\section{Acknowledgements}

This work is supported by the Australian Research Council through the Discovery Early Career Researcher Award Program (Number DE170100871) and the National Nature Science Foundation of China (Number 51574081).

\section{REFERENCES}

1. Deng D (2015) Li-ion batteries: basics, progress, and challenges. Energy Science \& Engineering 3(5): 385-418.

2. Choi JW and Aurbach D (2016) Promise and reality of post-lithiumion batteries with high energy densities. Nature Review Materials 1(4): 1-16.

3. Choi NS, Chen Z, Freunberger SA et al. (2012) Challenges facing lithium batteries and electrical double-layer capacitors. Angewandte Chemie International Edition 51(40): 9994-10024.

4. Dai X, Zhou AJ, Xu J et al. (2016) Extending the high-voltage capacity of $\mathrm{LiCoO}_{2}$ cathode by direct coating of the composite electrode with $\mathrm{Li}_{2} \mathrm{CO}_{3}$ via magnetron sputtering. Journal of Physical Chemistry C 120(1): 422-430.

5. Cho J, Kim YJ and Park B (2000) Novel $\mathrm{LiCoO}_{2}$ cathode material with $\mathrm{Al}_{2} \mathrm{O}_{3}$ coating for a $\mathrm{Li}$ ion cell. Chemistry of Materials 12(12): 3788-3791.

6. Peled E, Golodnitsky D and Ardel G (1997) Advanced model for solid electrolyte interphase electrodes in liquid and polymer electrolytes. Journal of the Electrochemical Society 144(8): L208-L210.

7. Verma P, Maire P and Novak P (2010) A review of the features and analyses of the solid electrolyte interphase in Li-ion batteries. Electrochimica Acta 55(22): 6332-6341.

8. Zhang HL, Li F, Liu C, Tan J and Cheng HM (2005) New insight into the solid electrolyte interphase with use of a focused ion beam. Journal of Physical Chemistry B 109(47): 22205-22211.

9. Zhang HL, Sun $\mathrm{CH}$, Li F et al. (2007) New insight into the interaction between propylene carbonate-based electrolytes and graphite anode material for lithium ion batteries. Journal of Physical Chemistry $C$ 111(12): 4740-4748.

10. Han CP, He YB, Liu M et al. (2017) A review of gassing behavior in $\mathrm{Li}_{4} \mathrm{Ti}_{5} \mathrm{O}_{12}$-based lithium ion batteries. Journal of Materials Chemistry A 5(14): 6368-6381.

11. Belharouak I, Koenig GM, Tan T et al. (2012) Performance degradation and gassing of $\mathrm{Li}_{4} \mathrm{Ti}_{5} \mathrm{O}_{12} / \mathrm{LiMn}_{2} \mathrm{O}_{4}$ lithium-ion cells. Journal of the Electrochemical Society 159(8): A1165-A1170.

12. Wen L, Wu ZY, Luo HZ, Song RS and Li F (2015) Dual functions of carbon in $\mathrm{Li}_{4} \mathrm{Ti}_{5} \mathrm{O}_{12} / \mathrm{C}$ microspheres. Journal of the Electrochemical Society 162(2): A3038-A3044.

13. Li W, Li X, Chen MZ et al. (2014) $\mathrm{AlF}_{3}$ modification to suppress the gas generation of $\mathrm{Li}_{4} \mathrm{Ti}_{5} \mathrm{O}_{12}$ anode battery. Electrochimica Acta 139(1): 104-110.

14. Han CP, He YB, Li HF et al. (2015) Suppression of interfacial reactions between $\mathrm{Li}_{4} \mathrm{Ti}_{5} \mathrm{O}_{12}$ electrode and electrolyte solution via zinc oxide coating. Electrochimica Acta 157(1): 266-273.

15. Li H, Wang ZX, Chen LQ and Huang XJ (2009) Research on advanced materials for Li-ion batteries. Advanced Materials 21(45): 4593-4607.

16. Kovalenko I, Zdyrko B, Magasinski A et al. (2011) A major constituent of brown algae for use in high-capacity Li-ion batteries. Science 334(6052): 75-79.

17. Choi S, Kwon TW, Coskun A and Choi JW (2017) Highly elastic binders integrating polyrotaxanes for silicon microparticle anodes in lithium ion batteries. Science 357(6348): 279-283.

18. Wang C, Wu H, Chen Z et al. (2013) Self-healing chemistry enables the stable operation of silicon microparticle anodes for high-energy lithium-ion batteries. Nature Chemistry 5(12): 1042-1048.

19. Ji XL and Nazar LF (2010) Advances in Li-S batteries. Journal of Materials Chemistry 20(44): 9821-9826.

20. Liang J, Yin LC, Tang XN et al. (2016) Kinetically enhanced electrochemical redox of polysulfides on polymeric carbon nitrides for improved lithium-sulfur batteries. ACS Applied Materials \& Interfaces 8(38): 25193-25201.

21. Liang J, Sun ZH, Li F and Cheng HM (2016) Carbon materials for $\mathrm{Li}-\mathrm{S}$ batteries: functional evolution and performance improvement. Energy Storage Materials 1(2): 76-106. 
22. Park KS, Benayad A, Kang DJ and Doo SG (2008) Nitridation-driven conductive $\mathrm{Li}_{4} \mathrm{Ti}_{5} \mathrm{O}_{12}$ for lithium ion batteries. Journal of the American Chemical Society 130(45): 14930-14932.

23. Arico AS, Bruce P, Scrosati B, Tarascon JM and Schalkwijk VW (2005) Nanostructured materials for advanced energy conversion and storage devices. Nature Materials 4(5): 366-377.

24. Eftekhari A (2017) $\mathrm{LiFePO}_{4} / \mathrm{C}$ nanocomposites for lithium-ion batteries. Journal of Power Sources 343(1): 395-411.

25. Zhu GN, Wang YG and Xia YY (2012) Ti-based compounds as anode materials for Li-ion batteries. Energy \& Environmental Sciences 5(5): 6652-6667.

26. Cheng L, Li XL, Liu HJ et al. (2007) Carbon-coated $\mathrm{Li}_{4} \mathrm{Ti}_{5} \mathrm{O}_{12}$ as a high rate electrode material for Li-ion intercalation. Journal of the Electrochemical Society 154(7): A692-A697.

27. Chi ZX, Zhang W, Wang XS et al. (2014) Accurate surface control of core-shell structured $\mathrm{LiMn}_{0.5} \mathrm{Fe}_{0.5} \mathrm{PO}_{4} @ \mathrm{C}$ for improved battery performance. Journal of Materials Chemistry A 2(41): 17359-17365.

28. Yang FL, Zhang W, Chi ZX et al. (2015) Controlled formation of core-shell structures with uniform $\mathrm{AlPO}_{4}$ nanoshells. Chemical Communications 51(14): 2943-2945.

29. Meng X, Yang XQ and Sun X (2012) Emerging applications of atomic layer deposition for lithium-ion battery studies. Advanced Materials 24(27): 3589-3615.

30. Dillon AC, Ott AW, Way JD and George SM (1995) Surface-chemistry of $\mathrm{Al}_{2} \mathrm{O}_{3}$ deposition using $\mathrm{Al}\left(\mathrm{CH}_{3}\right)_{3}$ and $\mathrm{H}_{2} \mathrm{O}$ in a binary reaction sequence. Surface Science 322(1-3): 230-242.

31. Scott ID, Jung YS, Cavanagh AS et al. (2011) Ultrathin coatings on nano-LiCoO $\mathrm{C}_{2}$ for Li-ion vehicular applications. Nano Letters 11(2) 414-418.

32. Liu J, Li XF, Cai M, Li RY and Sun XL (2013) Ultrathin atomic layer deposited $\mathrm{ZrO}_{2}$ coating to enhance the electrochemical performance of $\mathrm{Li}_{4} \mathrm{Ti}_{5} \mathrm{O}_{12}$ as an anode material. Electrochimica Acta $\mathbf{9 3 ( 3 0 )}$ : 195-201.
33. Park JS, Meng XB, Elam JW et al. (2014) Ultrathin lithium-ion conducting coatings for increased interfacial stability in high voltage lithium-ion batteries. Chemistry of Materials 26(10): 3128-3134.

34. Wang YG, Wang YR, Hosono E, Wang KX and Zhou HS (2008) The design of a $\mathrm{LiFePO}_{4} /$ carbon nanocomposite with a core-shell structure and its synthesis by an in situ polymerization restriction method. Angewandte Chemie International Edition 47(39): 7461-7465.

35. Xiao X, Lu P and Ahn D (2011) Ultrathin multifunctional oxide coatings for lithium ion batteries. Advanced Materials 23(34): 3911-3915.

36. Sun YK, Myung ST, Park BC et al. (2009) High-energy cathode material for long-life and safe lithium batteries. Nature Materials 8(4): 320-324.

37. Sun YK, Chen ZH, Noh HJ et al. (2012) Nanostructured high-energy cathode materials for advanced lithium batteries. Nature Materials 11(11): 942-947.

38. Wei QL, Wang XY, Yang XK et al. (2013) Spherical concentrationgradient $\mathrm{LiMn}_{1 \cdot 87} \mathrm{Ni}_{0 \cdot 13} \mathrm{O}_{4}$ spinel as a high performance cathode for lithium ion batteries. Journal of Materials Chemistry A 1(12): 4010-4016.

39. Liu W, Liu J, Chen KF et al. (2014) Enhancing the electrochemical performance of the $\mathrm{LiMn}_{2} \mathrm{O}_{4}$ hollow microsphere cathode with a $\mathrm{LiNi}_{0 \cdot 5} \mathrm{Mn}_{1 \cdot 5} \mathrm{O}_{4}$ coated layer. Chemistry - a European Journal 20(3): 824-830.

40. Kalluri S, Yoon M, Jo M et al. (2017) Feasibility of cathode surface coating technology for high-energy lithium-ion and beyond-lithiumion batteries. Advanced Materials 29(9): 1-12.

41. Zhao SX, Ding H, Wang YC, Li B and Nan CW (2013) Improving rate performance of $\mathrm{LiFePO}_{4}$ cathode materials by hybrid coating of nano$\mathrm{Li}_{3} \mathrm{PO}_{4}$ and carbon. Journal of Alloys and Compounds 566(25): 206-211.

42. Ren JG, Wu QH, Hong G et al. (2013) Silicon-graphene composite anodes for high-energy lithium batteries. Energy Technology 1(1): 77-84.

\section{How can you contribute?}

To discuss this paper, please submit up to 500 words to the journal office at journals@ice.org.uk. Your contribution will be forwarded to the author(s) for a reply and, if considered appropriate by the editor-in-chief, it will be published as a discussion in a future issue of the journal.

ICE Science journals rely entirely on contributions from the field of materials science and engineering. Information about how to submit your paper online is available at www.icevirtuallibrary.com/page/authors, where you will also find detailed author guidelines. 